\title{
Toxoplasma gondii Infection in Patients with Psychiatric Disorders from Western Romania
}

\author{
Sebastian Grada ${ }^{1,2,3,+}$, Alin Gabriel Mihu ${ }^{1,2,3,4,+}$, Cristina Petrescu ${ }^{5}$, Oana Suciu ${ }^{5}$, Iosif Marincu ${ }^{1}$, \\ Maria Alina Lupu 1,2,6,*(i) and Tudor Rares Olariu 1,2,7,*(D)
}

1 Discipline of Parasitology, Department of Infectious Disease, Victor Babes University of Medicine and Pharmacy, 300041 Timisoara, Romania; seba.grada@gmail.com (S.G.); alinmg@yahoo.com (A.G.M.); imarincu@umft.ro (I.M.)

2 Center for Diagnosis and Study of Parasitic Diseases, Victor Babes University of Medicine and Pharmacy, 300041 Timisoara, Romania

3 Department of Biology and Life Sciences, Vasile Goldis University of Medicine and Pharmacy, 310300 Arad, Romania

4 Bioclinica Medical Analysis Laboratory, Dreptatii Street, nr. 23, 310300 Arad, Romania

5 Department of Microbiology, Victor Babes University of Medicine and Pharmacy, 300041 Timisoara, Romania; cpetrescu64@yahoo.com (C.P.); oana_suciu96@yahoo.com (O.S.)

6 Clinical Laboratory, Institute of Cardiovascular Diseases, 300041 Timisoara, Romania

7 Clinical Laboratory, Municipal Clinical Emergency Teaching Hospital, 300041 Timisoara, Romania

* Correspondence: mariaalinalupu@gmail.com (M.A.L.); rolariu@yahoo.com (T.R.O.); Tel.: +40-744-610-615 (M.A.L.); +40-256-435555 (T.R.O.)

+ These authors contributed equally to this work.

check for updates

Citation: Grada, S.; Mihu, A.G.;

Petrescu, C.; Suciu, O.; Marincu, I.; Lupu, M.A.; Olariu, T.R. Toxoplasma gondii Infection in Patients with Psychiatric Disorders from Western Romania. Medicina 2022, 58, 208. https://doi.org/10.3390/ medicina58020208

Academic Editor: Nicola Luigi Bragazzi

Received: 30 December 2021

Accepted: 27 January 2022

Published: 30 January 2022

Publisher's Note: MDPI stays neutral with regard to jurisdictional claims in published maps and institutional affiliations.

Copyright: (C) 2022 by the authors. Licensee MDPI, Basel, Switzerland. This article is an open access article distributed under the terms and conditions of the Creative Commons Attribution (CC BY) license (https:// creativecommons.org/licenses/by/ $4.0 /)$.

\begin{abstract}
Background and Objectives: High rates of infection with Toxoplasma gondii were found in psychiatric patients globally. In this study, we assessed for the first time the prevalence of T. gondii infection in psychiatric patients and healthy individuals with no known psychiatric disorders in Western Romania. Materials and Methods: The presence of specific IgG anti-T. gondii antibodies was evaluated in 308 psychiatric patients and 296 control subjects using a chemiluminescence assay. Results: Overall, the seroprevalence of IgG antibodies was higher in psychiatric patients $(67.86 \%$; $209 / 308)$, compared with the control group $(54.05 \%$; 160/296) $(p<0.001)$. Our results revealed a significantly higher prevalence of $T$. gondii antibodies among patients with schizophrenia (69.77\%), organic (personality and behaviour) disorders (76.74\%), and mental disorders concerning alcohol abuse $(84.62 \%)$, compared with the control group $(p=0.009, p=0.005, p=0.043$, respectively). Conclusions: This study provides new and important information on the seroprevalence of $T$. gondii in Romanian psychiatric patients and may serve for further scientific research regarding the status of $T$. gondii infection in patients with psychiatric disorders.
\end{abstract}

Keywords: epidemiology; Western Romania; psychiatric patients; Toxoplasma gondii; serology

\section{Introduction}

About one-third of the world's population is infected with Toxoplasma gondii, the most common obligate intracellular protozoan parasite. T. gondii seroprevalence differs widely between countries [1-3]. Humans can be infected by ingestion or handling of undercooked or raw meat, ingestion of contaminated food or water [2,4], organ transplantation, via blood or leucocytes, or vertically from the acutely infected pregnant women to the foetus [2,5]. In immunocompetent subjects, the postnatally acquired T. gondii infection is generally considered clinically insignificant [3]. Under the pressure of the human's immune response [2], $T$. gondii will transform into intracellular cysts (in the liver, muscle, and neuronal cells) and will persist for the host's life [2,6]. It has been recently suggested that chronic infection with T. gondii in the brain correlates with changes in neuronal architecture, neurochemistry, and behaviour [7]. Several studies documented the connection between infection with T. gondii 
and certain mental health disorders such as schizophrenia [8], bipolar disease [9], suicide attempts [10], personality disorders [11] and episodes of self-directed violence [12].

In Western Romania, the seroprevalence of $T$. gondii antibodies in the general adult population is $64.8 \%$ [13], but limited data regarding the prevalence of $T$. gondii infection in Romanian psychiatric patients are currently available to the international medical community. Therefore, we evaluated the presence of specific IgG anti-T. gondii antibodies in psychiatric patients and control subjects.

\section{Materials and Methods}

\subsection{Study Design and Population}

A case-control study was conducted between 1 July 2018 and 31 July 2019. The study group included 308 consecutive psychiatric patients who were admitted to the Psychiatric Clinic of County Emergency Hospital in Arad, Romania. Clinical diagnoses were established in accordance with the Diagnostic and Statistical Manual of Mental Disorders, fifth edition (DSM-V) [14]. Mental illnesses were further classified using the International Classification of Disease, 10th Revision (ICD-10) codes (https:/ / www.icd10data.com/ICD1 0CM/Codes) (accessed on 29 December 2021).

The control group consisted of 296 consecutive volunteer blood donors, with no known psychiatric disorders, referred to the Regional Blood Transfusion Centre in Timisoara, Romania. All donors had to comply with the donation eligibility criteria set by the Romanian Ministry of Health [15].

This study was approved by the Ethics Committees of the Emergency County Hospital in Arad, Romania, and Victor Babes University Ethics Committee in Timisoara, Romania. All participants were aged over 18 years (with no upper age limit) and, after the study procedures and goals were carefully explained to them, they provided written informed consent. The sociodemographic characteristics (gender and age) were recorded for all subjects included in the study. The age given for each study participant is the age at which the serum sample was drawn.

\subsection{Serologic Tests}

Blood samples were collected at study enrolment, using the standard venepuncture method, into serum separation gel and clot activator vacuum tubes. The collected samples were then centrifuged at $4000 \times g$ for $10 \mathrm{~min}$, in 10 to $30 \mathrm{~min}$ after collection. The obtained sera were moved into sterile centrifuge Eppendorf tubes and stored at $-20{ }^{\circ} \mathrm{C}$ until tested.

T. gondii IgG antibodies were determined using chemiluminescence on Immulite 2000 analyser (Siemens Healthcare Diagnostics, Malvern, PA, USA). The test kits were used according to the manufacturer's protocol (including quality controls), and interpretation of the results was based on the manufacturer's criteria, as follows: $<6.5 \mathrm{IU} / \mathrm{mL}$, negative; $\geq 6.5 \mathrm{IU} / \mathrm{mL}$ to $7.99 \mathrm{IU} / \mathrm{mL}$, equivocal; $\geq 8 \mathrm{IU} / \mathrm{mL}$, positive. For the purpose of this study, equivocal results were considered negative.

\subsection{Statistical Analysis}

Data were recorded in a Microsoft Excel database, version 2011 (Microsoft Corp., Redmond, WA, USA). Statistical analyses were conducted using the Epi Info statistical package 3.3.2 (Centres for Disease Control and Prevention, Atlanta, GA, USA). Means, standard deviations, and proportions are presented. Crude odds ratios (ORs) and their $95 \%$ confidence intervals (95\% CIs) were calculated. To evaluate differences in T. gondii seroprevalence between groups, we used Mantel-Haenszel chi-square and two-tailed Fisher's exact tests, as appropriate. We consider $p<0.05$ statistically significant. 


\section{Results}

The 308 psychiatric patients included in the study group were aged between 19 and 63 years (mean age $=45.64 \pm 9.90$ years), and $142(46.10 \%)$ were males. The control group consisted of 296 subjects aged between 19 to 63 years (mean age $=45.29 \pm 9.94$ years), and $143(48.31 \%)$ were males (Table 1$)$. No statistically significant difference in age was found between cases and controls $(p=0.669)$.

Table 1. Demographic characteristics of the study group (psychiatric patients) and the control group (blood donors) included in the study.

\begin{tabular}{ccc}
\hline Characteristics & Study Group $(\boldsymbol{n = 3 0 8 , \mathbf { 1 0 0 } \% )}$ & Control Group $(\boldsymbol{n = 2 9 6 , \mathbf { 1 0 0 } \% )}$ \\
\hline Age $($ Mean \pm SD) & $45.64 \pm 9.90$ & $45.29 \pm 9.94$ \\
\hline Sex & $142(46.10 \%)$ & \\
Male & $166(53.90 \%)$ & $143(48.31 \%)$ \\
Female & & $153(51.69 \%)$ \\
Age Groups (years) & $24(7.79 \%)$ & $24(8.11 \%)$ \\
$19-29$ & $53(17.21 \%)$ & $53(17.91 \%)$ \\
$30-39$ & $96(31.17 \%)$ & $96(32.43 \%)$ \\
$40-49$ & $128(41.56 \%)$ & $116(39.19 \%)$ \\
$50-59$ & $7(2.27 \%)$ & $7(2.36 \%)$ \\
\hline 60 &
\end{tabular}

The seroprevalence of $T$. gondii increased with age, in both psychiatric patient and blood donor groups (data not shown). However, the overall seroprevalence of T. gondii IgG antibodies was significantly higher in psychiatric patients (67.86\% 209/308), compared with blood donors (54.05\%, 160/296, OR:1.79; 95\%CI: 1.29-2.50; $p<0.001)$ (Table 2).

Table 2. Seroprevalence of T. gondii IgG antibodies in the study and control groups, according to sex.

\begin{tabular}{ccccccc}
\hline & \multicolumn{2}{c}{ Psychiatric Patients (Study Group) } & \multicolumn{2}{c}{ Blood Donors (Control Group) } & \multirow{2}{*}{ OR (95\%CI) } & $p$ Value \\
\cline { 2 - 5 } & No. Positive (\%) & No. Negative (\%) & No. Positive (\%) & No. Negative (\%) & & $1.79(1.29-2.50)$ \\
\hline Total & $209(67.86 \%)$ & $99(32.14 \%)$ & $160(54.05 \%)$ & $136(45.95 \%)$ & $<0.001$ \\
\hline Sex & & & & & & \\
Male & $87(61.27 \%)$ & $55(38.73 \%)$ & $77(53.85 \%)$ & $66(46.15 \%)$ & $1.35(0.85-2.17)$ & 0.231 \\
Female & $122(73.49 \%)$ & $44(26.51 \%)$ & $83(54.25 \%)$ & $70(45.75 \%)$ & $2.33(1.46-3.74)$ & 0.001 \\
\hline
\end{tabular}

Further analysis with stratification by sex showed a higher significant difference in $T$. gondii seroprevalence between the psychiatric female patients and female controls $(73.49 \%$, 122/166 vs. $54.25 \%$, 83/153; OR: 2.33; 95\%CI: $1.46-3.74 ; p<0.001$ ), but no significant difference was found when psychiatric male patients were compared with male controls (61.27\%, 87/142 vs. 53.85\%, 77/143; OR: 1.35; 95\%CI: 0.85-2.17; $p=0.231$ ) (Table 2).

The seroprevalences of $T$. gondii IgG antibodies in patients according to their psychiatric disorder are presented in Table 3. When compared with the control group, a significantly higher prevalence of $T$. gondii antibodies was found among patients with schizophrenia $(69.77 \%$; OR $=1.96 ; 95 \% \mathrm{CI}$ : 1.17-3.28; $p=0.009)$, organic (personality and behaviour) disorders (76.74\%; OR $=2.81 ; 95 \% \mathrm{CI}: 1.33-5.90 ; p=0.005)$, and mental disorders concerning alcohol abuse $(84.62 \% ; \mathrm{OR}=4.68 ; 95 \% \mathrm{CI}$ : $1.02-21.46 ; p=0.043)$ (Table 3$)$. 
Table 3. Seroprevalence of Toxoplasma gondii IgG antibodies in psychiatric patients from Western Romania, according to diagnosis.

\begin{tabular}{|c|c|c|c|c|c|}
\hline Diagnosis & ICD-10 Diagnosis & Total No. Tested & No. Tested Positive (\%) & OR $(95 \% C I)$ & $p$ Value * \\
\hline Schizophrenia & F20.9 & 86 & $60(69.77 \%)$ & $1.96(1.17-3.28)$ & 0.009 \\
\hline Dementia & F03.90 & 4 & $2(50 \%)$ & $0.85(0.12-6.12)$ & 1 \\
\hline $\begin{array}{l}\text { Organic (personality and } \\
\text { behaviour) Disorders }\end{array}$ & F07.8 & 43 & $33(76.74 \%)$ & $2.81(1.33-5.90)$ & 0.005 \\
\hline Bipolar disorders & F31.9 & 20 & $11(55 \%)$ & $1.03(0.42-2.58)$ & 1 \\
\hline $\begin{array}{c}\text { Mental Disorder } \\
\text { concerning alcohol abuse }\end{array}$ & F10.1 & 13 & $11(84.62 \%)$ & $4.68(1.02-21.46)$ & 0.043 \\
\hline Depressive disorder & F33.0 & 75 & $48(64 \%)$ & $1.51(0.89-2.55)$ & 0.152 \\
\hline Delusional disorder & F05.8 & 18 & $14(77.78 \%)$ & $2.98(0.96-9.25)$ & 0.054 \\
\hline $\begin{array}{l}\text { Impulsive-control } \\
\text { disorder }\end{array}$ & F63.9 & 11 & $7(63.64 \%)$ & $1.49(0.43-5.19)$ & 0.759 \\
\hline Mood disorder & F06.3 & 30 & $18(60 \%)$ & $1.28(0.59-2.74)$ & 0.569 \\
\hline Adjustment disorder & $\mathrm{F} 43.2$ & 2 & $0(0 \%)$ & $\mathrm{NA}^{* *}$ & 0.214 \\
\hline Mental retardation & F78.8 & 6 & $5(83.33 \%)$ & $4.25(0.49-36.82)$ & 0.226 \\
\hline
\end{tabular}

* The seroprevalence of T. gondii IgG antibodies was compared with seroprevalence in control group. ${ }^{* *}$ not applicable.

\section{Discussion}

This is the first case-control study to evaluate the seroprevalence of T. gondii infection in Romanian psychiatric patients, compared with healthy blood donors. Blood donors were used as a control group due to the strict criteria [15]; they need to donate blood, which means their health conditions are as feasibly close as possible to the definition of the term 'healthy'. Our results revealed a high prevalence of T. gondii IgG antibodies in patients diagnosed with schizophrenia, organic (personality and behaviour) disorders, and mental disorders concerning alcohol abuse, compared with controls. Similar to the results of other studies conducted in this region $[4,13]$, the prevalence of $T$. gondii antibodies tended to increase with age in both groups: psychiatric patients and controls.

In immunocompetent individuals, T. gondii infection is generally asymptomatic. However, in recent years, a strong relationship has emerged between T. gondii infection and psychiatric disorders [16]. T. gondii, by direct stimulation of inflammatory cytokines in the central nervous system, can cause brain inflammation. It can also act on neurotransmitters (especially dopamine) that are involved in the development of psychosis and behavioural abnormalities [17]. Another hypothesis suggests that, in subjects infected with T. gondii, the onset of schizophrenia is triggered by an increased concentration of kynurenic acid (degradation product of tryptophan) which will inhibit glutamine and nicotine neurotransmitter receptors [18]. It has recently been suggested that chronic infection with $T$. gondii in the brain correlates with changes in neuronal architecture, neurochemistry, and behaviour [7].

The results of studies regarding the association between T. gondii infection and psychiatric disorders are controversial. Although this association has been confirmed by many studies [19-25], there are published data that suggest a lack of association [16,18,26-29].

In the present study, we found a $67.86 \%$ seroprevalence of $T$. gondii IgG antibodies among Romanian psychiatric patients, higher than the $54.7 \%$ prevalence recently reported in patients with psychiatric disorders diagnosed in Western Romania [30].

The potential association of $T$. gondii infection with schizophrenia found in our study has previously been demonstrated by many authors [16,30-32]. However, unlike other studies [33,34], we found no association between the seroprevalence of T. gondii and bipolar disorder. Consistent with our findings, Yolken et al. revealed that individuals diagnosed with a delusional disorder had significantly increased seroprevalence of $T$. gondii $\operatorname{IgG}$ antibodies, compared with controls, and did not differ significantly in individuals with bipolar disorder [29]. The concept that T. gondii seropositivity is lifelong has been called into question by some authors, who suggested that persistent exposure to the parasite is required for the maintenance of antibody levels [35]. Moreover, medications used to treat 
schizophrenia or bipolar disorder have anti-Toxoplasma activity in cell culture and can lead to the decline in T. gondii seropositivity over time [36].

Our results revealed no difference in the seroprevalence of $T$. gondii antibodies in patients diagnosed with depressive disorders, compared with blood donors, and are in contrast with the findings reported by Alvarado-Esquivel et al. [37]. Further studies should be conducted to assess the potential relationship of $T$. gondii with depressive disorders since recent data suggest that no association can be found between latent $T$. gondii infection and major depressive disorders [38]. It has been previously shown that $T$. gondii may cause depression and mood disorders by affecting serotonin and/or dopamine biosynthesis, the tryptophan metabolism, and the hypothalamic-pituitary-adrenal axis [39]. In the present study, a significant difference in $T$. gondii seroprevalence was found between patients diagnosed with mental disorders concerning alcohol abuse and healthy blood donors. Our results are consistent with those found by Samojłowicz et al. [40] and EstradaMartinez et al. [41] but inconsistent with the results published by Suvisaari et al. [42], who found no association between T. gondii seropositivity and alcohol abuse.

T. gondii past infection was not found to be related to mental retardation in our study group, similar to results published by Ezatpour et al. [43].

In contrast with the results published by other authors [7,19,37], we found a higher seroprevalence of $T$. gondii antibodies in females with psychiatric disorders, compared with females from the control group. No questionnaire was used in this study to identify the risk factors associated with $T$. gondii, and therefore, we cannot explain the difference in seroprevalence. Further epidemiological surveys should be conducted to identify the potential risk factors for T. gondii infection in psychiatric patients.

\section{Conclusions}

Results of the present study indicate a significantly higher T. gondii IgG seroprevalence rate in psychiatric patients, compared with controls. The prevalence of T. gondii IgG antibodies was higher in patients diagnosed with schizophrenia, organic (personality and behaviour) disorders, and mental disorders concerning alcohol abuse. This study brings new and important data regarding the seroprevalence of $T$. gondii in patients with psychiatric diseases. Further epidemiological studies are needed to assess the risk factors for toxoplasmosis in psychiatric patients to better understand the potential relationship between T. gondii infection and psychiatric disorders.

Author Contributions: Conceptualisation, T.R.O.; methodology, T.R.O. and M.A.L.; software T.R.O., M.A.L. and A.G.M.; validation, T.R.O., A.G.M. and M.A.L.; formal analysis, T.R.O., A.G.M., S.G., I.M. and M.A.L.; investigation, S.G., A.G.M., C.P., O.S., M.A.L. and T.R.O.; resources, S.G. and T.R.O.; data curation, T.R.O., M.A.L. and A.G.M.; writing-original draft preparation, S.G., A.G.M., M.A.L. and T.R.O.; writing-review and editing, S.G., T.R.O., A.G.M., C.P., O.S., I.M. and M.A.L.; visualisation, T.R.O., S.G., A.G.M. and M.A.L.; supervision, S.G., M.A.L. and T.R.O.; project administration, T.R.O. All authors have read and agreed to the published version of the manuscript.

Funding: No external funding was received.

Institutional Review Board Statement: The study was conducted in accordance with the guidelines of the Declaration of Helsinki, and approved by Ethics Committees of the Emergency County Hospital in Arad, Romania (No. 8051/16.03.2018) and Victor Babes University Ethics Committee in Timisoara, Romania (No. 05/16.01.2018).

Informed Consent Statement: Informed consent was obtained from all subjects involved in the study.

Data Availability Statement: Datasets used and/or analysed during the current study are available from the corresponding author on reasonable request.

Conflicts of Interest: The authors declare no conflict of interest. 


\section{References}

1. Yolken, R.H.; Dickerson, F.B.; Fuller Torrey, E. Toxoplasma and schizophrenia. Parasite Immunol. 2009, 31, 706-715. [CrossRef] [PubMed]

2. $\quad$ Montoya, J.G.; Liesenfeld, O. Toxoplasmosis. Lancet 2004, 363, 1965-1976. [CrossRef]

3. Flegr, J.; Horáček, J. Negative Effects of Latent Toxoplasmosis on Mental Health. Front Psychiatry 2020, 10, 1012. [CrossRef] [PubMed]

4. Mihu, A.G.; Balta, C.; Marti, D.T.; Paduraru, A.A.; Lupu, M.A.; Olariu, T.R. Seroprevalence of Toxoplasma gondii infection among women of childbearing age in an endemic region of Romania, 2016-2018. Parasite 2020, 27, 59. [CrossRef] [PubMed]

5. Olariu, T.R.; Press, C.; Talucod, J.; Olson, K.; Montoya, J.G. Congenital toxoplasmosis in the United States: Clinical and serologic findings in infants born to mothers treated during pregnancy. Parasite 2019, 26, 13. [CrossRef] [PubMed]

6. Dubey, J.P. Advances in the life cycle of Toxoplasma gondii. Int. J. Parasitol. 1998, 28, 1019-1024. [CrossRef]

7. Alvarado-Esquivel, C.; Estrada-Martínez, S.; Pérez-Alamos, A.R. A Case-Control Seroprevalence Study on the Association between Toxoplasma gondii Infection and Bipolar Disorder. Front Psychiatry 2019, 10, 766. [CrossRef]

8. Hinze-Selch, D. Toxoplasma gondii infection and neuropsychiatric disease: Current insight. Rep. Parasitol. 2015, 4, 43-51. [CrossRef]

9. Pearce, B.D.; Kruszon-Moran, D.; Jones, J.L. The relationship between Toxoplasma gondii infection and mood disorders in the third National Health and Nutrition Survey. Biol. Psychiatry 2012, 72, 290-295. [CrossRef]

10. Arling, T.A.; Yolken, R.H.; Lapidus, M.; Langenberg, P.; Dickerson, F.B.; Zimmerman, S.A.; Balis, T.; Cabassa, J.A.; Scranis, D.A.; Tonelli, L.H.; et al. Toxoplasma gondii antibody titers and history of suicide attempts in patients with recurrent mood disorders. J. Nerv. Ment. Dis. 2009, 197, 905-908. [CrossRef]

11. Hinze-Selch, D.; Däubener, W.; Erdag, S.; Wilms, S. The diagnosis of a personality disorder increases the likelihood for seropositivity to Toxoplasma gondii in psychiatric patients. Folia Parasitol. 2010, 57, 129-135. [CrossRef] [PubMed]

12. Pedersen, M.G.; Mortensen, P.B.; Norgaard-Pedersen, B.; Postolache, T.T. Toxoplasma gondii infection and self-directed violence in mothers. Arch. Gen. Psychiatry 2012, 69, 1123-1130. [CrossRef] [PubMed]

13. Olariu, T.R.; Petrescu, C.; Darabus, G.; Lighezan, R.; Mazilu, O. Seroprevalence of Toxoplasma gondii in Western Romania. Infect. Dis. 2015, 47, 580-583. [CrossRef] [PubMed]

14. American Psychiatric Association. Diagnostic and Statistical Manual of Mental Disorders, 5th ed.; American Psychiatric Association: Washington, DC, USA; London, UK, 2013.

15. Ministerul Sănătăţii Publice din Romania. ORDIN Nr. 1193 din 7 Iulie 2007 Pentru Aprobarea Normelor Privind Informaţiile Care Trebuie Oferite Donatorilor de Sânge şi de Componente Sanguine de Origine Umană, Precum şi Informaţiile Care Trebuie Comunicate de Către Donatori la Fiecare Donare şi Admisibilitatea Donatorilor de Sânge şi de Componente Sanguine Umane. (Romanian Ministry of Public Health. ORDER Nr. 1193 of July 7, 2007 for the Approval of the Rules on the Information to be Provided to Donors of Blood and Blood Components of Human Origin, as Well as the Information to Be Communicated by Donors at Each Donation and the Admissibility of Donors of Human Blood and Blood Components). Available online: http:/ / legislatie.just.ro/Public/DetaliiDocumentAfis/117980 (accessed on 29 December 2021). (In Romanian).

16. Sutterland, A.L.; Fond, G.; Kuin, A.; Koeter, M.W.; Lutter, R.; van Gool, T.; Yolken, R.; Szoke, A.; Leboyer, M.; de Haan, L. Beyond the association. Toxoplasma gondii in schizophrenia, bipolar disorder, and addiction: Systematic review and meta-analysis. Acta Psychiatr. Scand. 2015, 132, 161-179. [CrossRef]

17. Del Grande, C.; Galli, L.; Schiavi, E.; Dell'Osso, L.; Bruschi, F. Is Toxoplasma gondii a Trigger of Bipolar Disorder? Pathogens 2017, 6, 3. [CrossRef] [PubMed]

18. Flegr, J. Neurological and Neuropsychiatric Consequences of Chronic Toxoplasma Infection. Curr. Clin. Microbiol. Rep. 2015, 2, 163-172. [CrossRef]

19. Chen, X.; Chen, B.; Hou, X.; Zheng, C.; Yang, X.; Ke, J.; Hu, X.; Tan, F. Association between Toxoplasma gondii infection and psychiatric disorders in Zhejiang, Southeastern China. Acta Trop. 2019, 192, 82-86. [CrossRef]

20. El Mouhawess, A.; Hammoud, A.; Zoghbi, M.; Hallit, S.; Haddad, C.; El Haddad, K.; El Khoury, S.; Tannous, J.; Obeid, S.; Halabi, M.A.; et al. Relationship between Toxoplasma gondii seropositivity and schizophrenia in the Lebanese population: Potential implication of genetic polymorphism of MMP-9. BMC Psychiatry 2020, 20, 264.

21. Fuglewicz, A.J.; Piotrowski, P.; Stodolak, A. Relationship between toxoplasmosis and schizophrenia: A review. Adv. Clin. Exp. Med. 2017, 26, 1031-1036. [CrossRef]

22. Stepanova, E.V.; Kondrashin, A.V.; Sergiev, V.P.; Morozova, L.F.; Turbabina, N.A.; Maksimova, M.S.; Romanov, D.V.; Kinkulkina, M.A.; Lazareva, A.V.; Morozov, E.N. Toxoplasmosis and mental disorders in the Russian Federation (with special reference to schizophrenia). PLoS ONE 2019, 10, e0219454. [CrossRef]

23. Del Grande, C.; Schiavi, E.; Masci, I.; Barbuti, M.; Maccariello, G.; Massimetti, G.; Bruschi, F.; Dell'Osso, L. Toxoplasmosis in a Cohort of Italian Patients With Bipolar and Psychotic Disorders: How Infection May Affect Clinical Features? J. Nerv. Ment. Dis. 2020, 208, 118-126. [CrossRef] [PubMed]

24. Achaw, B.; Tesfa, H.; Zeleke, A.J.; Worku, L.; Addisu, A.; Yigzaw, N.; Tegegne, Y. Sero-prevalence of Toxoplasma gondii and associated risk factors among psychiatric outpatients attending University of Gondar Hospital, Northwest Ethiopia. BMC Infect. Dis. 2019, 19, 581. [CrossRef] [PubMed] 
25. Snijders, G.J.L.J.; van Mierlo, H.C.; Boks, M.P.; Begemann, M.J.H.; Sutterland, A.L.; Litjens, M.; Ophoff, R.A.; Kahn, R.S.; de Witte, L.D. The association between antibodies to neurotropic pathogens and bipolar disorder: A study in the Dutch Bipolar (DB) Cohort and meta-analysis. Transl. Psychiatry 2019, 9, 311. [CrossRef] [PubMed]

26. Gale, S.D.; Brown, B.L.; Berrett, A.; Erickson, L.D.; Hedges, D.W. Association between latent toxoplasmosis and major depression, generalised anxiety disorder and panic disorder in human adults. Folia Parasitol. 2014, 61, 285-292. [CrossRef]

27. Flegr, J.; Hodný, Z. Cat scratches, not bites, are associated with unipolar depression-cross-sectional study. Parasit. Vectors 2016, 9 , 8. [CrossRef]

28. Mortensen, P.B.; Nørgaard-Pedersen, B.; Waltoft, B.L.; Sørensen, T.L.; Hougaard, D.; Torrey, E.F.; Yolken, R.H. Toxoplasma gondii as a risk factor for early-onset schizophrenia: Analysis of filter paper blood samples obtained at birth. Biol. Psychiatry 2007, 61, 688-693. [CrossRef]

29. Yolken, R.; Torrey, E.F.; Dickerson, F. Evidence of increased exposure to Toxoplasma gondii in individuals with recent onset psychosis but not with established schizophrenia. PLoS Negl. Trop. Dis. 2017, 11, e0006040. [CrossRef]

30. Olariu, T.; Capraru, I.; Papava, I.; Romosan, R.; Dehelean, L.; Lupu, M.A. Seroprevalence of toxoplasma gondii in Romanian psychiatric patients. Eur. Psychiatry 2017, 41 (Suppl. S1), S825. [CrossRef]

31. Esshili, A.; Thabet, S.; Jemli, A.; Trifa, F.; Mechri, A.; Zaafrane, F.; Gaha, L.; Juckel, G.; Babba, H.; Bel Hadj Jrad, B. Toxoplasma gondii infection in schizophrenia and associated clinical features. Psychiatry Res. 2016, 245, 327-332. [CrossRef]

32. Yonghua, Z.; Yue, C.; Lei, Z.; Qi, G. Analysis of probable correlation between Toxoplasma gondii and schizophrenia: A seroepidemiological longitudinal investigation from 2002 to 2007 in Suzhou and Wuxi regions, Jiangsu, China. Trop. Med. Int. Health 2011, 16, 367-368.

33. Hamdani, N.; Daban-Huard, C.; Lajnef, M.; Richard, J.R.; Delavest, M.; Godin, O.; Le Guen, E.; Vederine, F.E.; Lépine, J.P.; Jamain, S.; et al. Relationship between Toxoplasma gondii infection and bipolar disorder in a French sample. J. Affect. Disord. 2013, 148, 444-448. [CrossRef] [PubMed]

34. $\quad$ Lin, H.A.; Chien, W.C.; Huang, K.Y.; Chung, C.H.; Chen, L.C.; Lin, H.C.; Guo, J.L. Infection with Toxoplasma gondii increases the risk of psychiatric disorders in Taiwan: A nationwide population-based cohort study. Parasitology. 2020, 147, 1577-1586. [CrossRef] [PubMed]

35. Rougier, S.; Montoya, J.G.; Peyron, F. Lifelong Persistence of Toxoplasma Cysts: A Questionable Dogma? Trends Parasitol. 2017, 33, 93-101. [CrossRef] [PubMed]

36. Jones-Brando, L.; Torrey, E.F.; Yolken, R. Drugs used in the treatment of schizophrenia and bipolar disorder inhibit the replication of Toxoplasma gondii. Schizophr Res. 2003, 62, 237-244. [CrossRef]

37. Alvarado-Esquivel, C.; Sánchez-Anguiano, L.F.; Hernández-Tinoco, J.; Berumen-Segovia, L.O.; Torres-Prieto, Y.E.; EstradaMartínez, S.; Pérez-Álamos, A.R.; Ortiz-Jurado, M.N.; Molotla-de-León, G.; Beristain-García, I.; et al. Toxoplasma Gondii Infection and Depression: A Case-Control Seroprevalence Study. Eur. J. Microbiol. Immunol. 2016, 6, 85-89. [CrossRef] [PubMed]

38. Nayeri Chegeni, T.; Sharif, M.; Sarvi, S.; Moosazadeh, M.; Montazeri, M.; Aghayan, S.A.; Balalami, N.J.; Gholami, S.; Hosseininejad, Z.; Saberi, R.; et al. Is there any association between Toxoplasma gondii infection and depression? A systematic review and meta-analysis. PLoS ONE 2019, 14, e0218524. [CrossRef] [PubMed]

39. Henriquez, S.A.; Brett, R.; Alexander, J.; Pratt, J.; Roberts, C.W. Neuropsychiatric disease and Toxoplasma gondii infection. Neuroimmunomodulation 2009, 16, 122-133. [CrossRef] [PubMed]

40. Samojłowicz, D.; Borowska-Solonynko, A.; Kruczyk, M. New, previously unreported correlations between latent Toxoplasma gondii infection and excessive ethanol consumption. Forensic Sci. Int. 2017, 280, 49-54. [CrossRef]

41. Estrada-Martinez, S.; Pérez-Álamos, A.R.; Ibarra-Segovia, M.; Beristaín-Garcia, I.; Ramos-Nevárez, A.; Saenz-Soto, L.; RábagoSánchez, E.; Guido-Arreola, C.A.; Alvarado-Esquivel, C. Seroepidemiology of Toxoplasma gondii infection in people with alcohol consumption in Durango, Mexico. PLoS ONE 2021, 16, e245701. [CrossRef]

42. Suvisaari, J.; Torniainen-Holm, M.; Lindgren, M.; Härkänen, T.; Yolken, R.H. Toxoplasma gondii infection and common mental disorders in the Finnish general population. J. Affect. Disord. 2017, 223, 20-25. [CrossRef]

43. Ezatpour, B.; Zibaie, M.; Rahmati, H.; Pournia, Y.; Azami, M.; Ebrahimzadeh, F.; Azadpour, M.; Ghalesefidi, M.J. Seroprevalence of toxoplasmosis in mentally retarded patients in Iranian rehabilitation centers. J. Parasit. Dis. 2015, 39, 13-17. [CrossRef] [PubMed] 